\title{
DESDOBRAMENTOS DOS RELATÓRIOS DAS AVALIAÇÕES EM LARGA ESCALA
}

KARINA ALVES BIASOLI STANICH CLARILZA PRADO DE SOUSA

\section{RESUMO}

A partir dos relatórios das avaliações em larga escala realizadas, ao longo de seis anos, por um sistema de ensino da rede privada, analisaram-se o desempenho dos alunos em Geometria e o modo como os professores identificavam e representavam as dificuldades dos estudantes. Foram entrevistados 24 professores do $5^{\circ}$ ano do ensino fundamental, de 18 unidades escolares do estado de São Paulo. 0 estudo foi elaborado sob o aporte teórico da Teoria das Representações Sociais, do modelo van Hiele e dos critérios de avaliação propostos pelo Programme for International Student Assessment de 2003 e 2012. Os resultados evidenciam uma representação de impossibilidade de aprendizagem dos alunos do $5^{\circ}$ ano, resultando no deslocamento do objetivo do ensino, que, reduzido à sua aplicação prática e ao contexto imediato do aluno, não favorecia o desenvolvimento das habilidades de representar e operar teoricamente sobre o cotidiano.

PALAVRAS-CHAVE AVALIAÇÃO EM LARGA ESCALA • REPRESENTAÇÕES SOCIAIS • ENSINO • GEOMETRIA. 


\title{
DESDOBLAMIENTOS DE LOS INFORMES DE LAS EVALUACIONES EN LARGA ESCALA
}

RESUMEN

A partir de los informes de las evaluaciones en larga escala realizadas a lo largo de seis años por un sistema de enseñanza de la red privada, se analizaron el desempeño de los alumnos en Geometría y el modo en el que los profesores identificaban y representaban las dificultades de los estudiantes. Se entrevistaron 24 docentes del $5^{\circ}$ año de la educación básica de 18 unidades escolares del estado de São Paulo. El estudio fue elaborado con el aporte teórico de la Teoría de las Representaciones Sociales, del modelo van Hiele y de los criterios de evaluación propuestos por el Programme for International Student Assessment de 2003 y 2012. Los resultados ponen de manifiesto una representación de imposibilidad de aprendizaje de los alumnos del $5^{\circ}$ año, lo que resultó en el desplazamiento del objetivo de la enseñanza que, reducido a su aplicación práctica y al contexto inmediato del aluno, no favorecía el desarrollo de las habilidades de representar y operar teóricamente sobre el cotidiano.

PALABRAS CLAVE EVALUACIÓN EN LARGA ESCALA - REPRESENTACIONES SOCIALES • ENSEÑANZA • GEOMETRÍA.

\section{UNFOLDING THE REPORTS OF EVALUATIONS ON A LARGE SCALE}

\begin{abstract}
Based on reports conducted over a six-year period of evaluations on a large scale, carried out by a private educational system, students' performance in Geometry as well as the way teachers identified and represented their difficulties were analyzed. Twenty-four fifth grade teachers, from 18 schools in the state of São Paulo, were interviewed. The study was developed based on the Theory of Social Representations of the van Hiele model and the evaluation criteria proposed the Programme for International Student Assessment of 2003 and 2012. The results showed a representation of the impossibility of fifth grade students to learn, resulting in the displacement of the aim of instruction which, reduced to its practical application and the immediate context of the student, did not support the development of skills to represent and theoretically deal with everyday life.
\end{abstract}

KEYWORDS LARGE SCALE EVALUATION • SOCIAL REPRESENTATIONS • TEACHING • GEOMETRY. 


\section{INTRODUÇÃO}

O presente texto parte de dois projetos mais amplos, desenvolvidos respectivamente por Sousa et al. (2012) e Stanich (2013), que tiveram como ponto de partida a análise dos resultados de avaliações em larga escala, realizadas em 2003, 2005 e 2008 por um sistema de ensino da rede privada.

No estudo desenvolvido por Sousa et al. (2012), foram analisados os resultados das avaliações centradas na área da Matemática, possibilitando a identificação de oito descritores de Matemática nos quais os alunos do $5^{\circ}$ ano mostravam um índice de acerto inferior a 50\% em duas ou mais avaliações.

O presente estudo buscou compreender como os professores identificavam e representavam as dificuldades dos seus alunos em Matemática, considerando-se, conforme proposto por Werle (2010), que as análises dos resultados das avaliações em larga escala, quando realizadas em conjunto com os professores, podem ser o início de um trabalho que resulte na melhoria do ensino, com definição dos pontos que precisam ser discutidos, aproximando os dados numéricos resultantes dessas avaliações à realidade da escola, dos 
alunos e dos professores. Para tanto, foram selecionados e entrevistados 24 professores do $5^{\circ}$ ano do ensino fundamental de 18 unidades escolares situadas em diferentes regiões do Estado de São Paulo.

As análises realizadas por Sousa et al. (2012) permitiram um olhar abrangente acerca do modo como as dificuldades recorrentes dos alunos do $5^{\circ}$ ano em Matemática eram identificadas e representadas por seus professores, justamente por compor um banco de dados coletados abrangendo: as percepções dos participantes sobre os conteúdos de cada descritor; a descrição da dificuldade percebida em seus alunos; a enumeração das atividades e estratégias utilizadas para sanar tais dificuldades; emoções, sentimentos e desabafos sobre as condições de trabalho e de formação profissional; e justificativas para a não aprendizagem dos seus alunos.

A partir do banco de dados mencionado, dos oito descritores com índice de acerto inferior a $50 \%$ em duas ou três avaliações, foram selecionados os dois que se referiam à Geometria, conforme demonstrado no Quadro 1.

QUADRO 1 - Descritores das habilidades em que os alunos do $5^{\circ}$ ano do ensino fundamental apresentaram um índice de acerto inferior a $50 \%$ em pelo menos duas avaliações

\begin{tabular}{|c|c|c|c|}
\hline DESCRITOR & HABILIDADES & $\begin{array}{l}\text { NÚMERO DE } \\
\text { RECORRÊNCIAS } \\
\text { DA DIFICULDADE }\end{array}$ & $\begin{array}{c}\text { ANOS DE } \\
\text { AVALIAÇÃO }\end{array}$ \\
\hline 1 & $\begin{array}{l}\text { Identificar semelhanças e diferenças entre } \\
\text { figuras tridimensionais, distinguindo pirâmides } \\
\text { de prismas, fazendo contagem do número de } \\
\text { vértices, arestas ou faces nos poliedros. }\end{array}$ & duas avaliações & $2003 / 2008$ \\
\hline 2 & $\begin{array}{l}\text { Identificar características de figuras } \\
\text { bidimensionais como o tipo de contorno que } \\
\text { as delimita. }\end{array}$ & três avaliações & $2003 / 2005 / 2008$ \\
\hline
\end{tabular}

Fonte: Relatório de avaliação externa dos anos 2003 (Fundação Carlos Chagas - FCC), 2005 e 2008 (Centro de Seleção e de Promoção de Eventos - Cespe/Universidade de Brasília - UnB).

No presente estudo procurou-se construir um quadro explicativo que permitisse maior aprofundamento sobre o modo como os professores identificavam e representavam as dificuldades dos seus alunos em Geometria, a partir dos processos sociais que a informavam, de tal modo que abrangesse o objeto representacional não como elemento individualizado, em que é considerado apenas o baixo desempenho dos alunos, mas sim, como propõe Arruda (2005, p. 246), 
levando em conta sua complexidade, o que implica observar o perfil dos professores e suas percepções sobre condições de trabalho, formação inicial e continuada, material didático utilizado e suas próprias dificuldades no trabalho com os conteúdos geométricos.

Nas palavras de Moscovici (2010, p. 17), o objeto representacional deve ser contemplado como "sistema de valores, ideias e práticas" que resultam do entrelaçamento de diferentes processos sociais construídos não apenas "nos espaços formativos, mas também nas atividades e nos discursos cotidianos" (PIMENTA; DIAS, 2012, p. 116), constituindo a base de toda e qualquer ação.

De modo a contemplar um aprofundamento que articulasse os elementos afetivos, mentais e sociais, integrando a cognição, a linguagem e a comunicação às relações sociais, conforme proposto por Spink (2012, p. 98), para o presente texto foram selecionadas quatro etapas distintas de análise, didaticamente organizadas e a seguir apresentadas.

\section{$1{ }^{a}$ ETAPA: ANÁLISE DO PERFIL DOS ENTREVISTADOS}

Dos 24 professores participantes, sete trabalhavam em escolas cujo desempenho havia sido considerado "baixo"; sete encontravam-se em escolas que apresentaram desempenho "alto"; e dez estavam em escolas que obtiveram um desempenho médio.

Em relação ao tempo de docência, quatro dos entrevistados possuíam 1 a 7 anos de docência, 13 possuíam de 8 a 23 anos de docência e 7 tinham 24 anos ou mais de experiência como docentes.

Sobre a formação superior dos participantes, 23 deles eram formados em Pedagogia. Quanto ao fato de terem cursado ou não o magistério (curso técnico de formação de professores, equivalente ao ensino médio), notou-se que 19 deles não haviam cursado, sendo apenas cinco os que apresentavam a referida formação na modalidade de habilitação do ensino médio. Sobre possuir ou não um curso de especialização, 15 dos respondentes afirmaram ter algum curso de especialização na área da educação e nove informaram não possuir tal formação. 
A partir do perfil dos participantes, percebeu-se que 20 dos entrevistados (83\%) possuíam um tempo de experiência na docência superior a oito anos, 23 (96\%) tinham formação superior em Pedagogia e 15 (63\%) apresentavam algum curso complementar de especialização na área da educação. Tais elementos foram importantes por descreverem um grupo que apresentava ampla experiência no magistério e permitirem localizar temporalmente os períodos de suas formações como estudantes e professores.

No entanto, ao resgatar a historicidade sobre o modo como o ensino da Geometria foi considerado ao longo das diferentes reformas curriculares nacionais, pode-se constatar que esses professores, em sua formação como estudantes e, posteriormente, como professores, não foram contemplados com o ensino da Geometria, corroborando o resultado dos estudos desenvolvidos por Nacarato, que indicam que os professores que tiveram suas formações nos anos 1980 e 1990, em escolas públicas e privadas, não vivenciaram o ensino de Geometria, e,

[...] quando o vivenciaram, foi um ensino reducionista e simplista, limitado ao reconhecimento e identificação de formas, sem levar em consideração a complexidade do pensamento geométrico. (NACARATO, 2000, p. 159)

\section{2a ETAPA: DESCRIÇÃO E ANÁLISE DAS DIFICULDADES DOS} ALUNOS APONTADAS PELOS PROFESSORES

Tendo em vista que os resultados dos relatórios das avaliações em larga escala realizadas entre os anos 2003, 2005 e 2008 apontaram índices de acerto inferiores a 50\% nos descritores do campo geométrico que constam do Quadro 1, nessa etapa buscou-se compreender em que medida os professores do $5^{\circ}$ ano reconheciam os referidos descritores como sendo uma dificuldade dos seus alunos e identificavam/apontavam tais dificuldades, conforme tabelas 1 e 2 . 
TABELA 1 - Número de respondentes de acordo com a percepção sobre a dificuldade dos alunos em relação aos descritores do campo geométrico apresentados no Quadro 1

\begin{tabular}{l|c|c}
\hline $\begin{array}{l}\text { PERCEPÇÃO SOBRE A EXISTÊNCIA } \\
\text { DA DIFICULDADE }\end{array}$ & DESCRITOR 1 & DESCRITOR 2 \\
\hline Reconhece o descritor como dificuldade & 11 & 8 \\
\hline Não reconhece o descritor como dificuldade & 12 & 11 \\
\hline Não respondeu à questão & 1 & 5 \\
\hline Total & 24 & 24 \\
\hline
\end{tabular}

Fonte: Dados organizados pelas autoras.

Apenas 11 professores reconheceram o descritor 1 como uma dificuldade para os seus alunos e, para o descritor 2, esse número é ainda mais reduzido, totalizando oito participantes.

No que concerne à quantidade de participantes que, além de reconhecerem o descritor como uma dificuldade para os seus alunos, conseguiram especificar o tipo de dificuldade relacionada aos descritores do campo geométrico, observa-se um número ainda mais reduzido, conforme Tabela 2.

TABELA 2 - Número de respondentes, dentre aqueles que reconhecem que os descritores do campo geométrico apresentados no Quadro 1 representam uma dificuldade para os alunos, que são capazes de especificar tais deficiências

\begin{tabular}{l|c|c}
\hline $\begin{array}{l}\text { PERCEPÇÃO SOBRE A NATUREZA } \\
\text { DA DIFICULDADE }\end{array}$ & DESCRITOR 1 & DESCRITOR 2 \\
\hline Especifica a dificuldade dos alunos & 5 & 3 \\
\hline Não especifica a dificuldade dos alunos & 6 & 5 \\
\hline Total & 11 & 8 \\
\hline
\end{tabular}

Fonte: Dados organizados pelas autoras.

Observa-se que, dos 24 participantes, apenas cinco apontaram e especificaram as dificuldades dos seus alunos, em relação ao descritor 1, e somente três, no tocante ao descritor 2.

Embora os relatórios dos resultados das avaliações analisadas indicassem a recorrência da dificuldade dos alunos nos descritores do campo geométrico ao longo de seis anos, apenas um número reduzido de professores foi capaz de reconhecê-las e especificá-las como tal.

$\mathrm{Na}$ medida em que os professores não reconheciam os descritores como uma dificuldade e não conseguiam identificar 
exatamente quais eram as dificuldades dos seus alunos, reduzidas seriam as possibilidades de intervenção no sentido de superá-las, prejudicando a construção de uma estratégia que permitisse $o$ avanço da aprendizagem, conforme proposto por Roldão (2010).

Considerar e identificar as dificuldades dos alunos implicaria um conhecimento, por parte do grupo, dos conteúdos geométricos envolvidos em tais descritores, de aprofundamentos teóricos sobre o modo como se dá a aprendizagem de tais conteúdos, das competências e habilidades requeridas, dos níveis de aplicação dos conteúdos geométricos e, ainda, das estratégias e orientações de ensino, amplamente exploradas nas avaliações de 2003 e 2012 pelo Programme for International Student Assessment (Pisa) e pelo modelo de desenvolvimento do pensamento geométrico proposto por van Hiele (1999) e que não foram contemplados nos relatórios das avaliações em larga escala analisados.

Nessa etapa, as dificuldades dos alunos em Geometria, apontadas por seus professores, foram listadas e analisadas a partir dos níveis de competência, complexidade e contextos propostos pelo Pisa, nas avaliações com concentração em Matemática realizadas em 2003 e 2012, e dos níveis de desenvolvimento do pensamento geométrico sugeridos pelo modelo van Hiele (1999).

Essa opção justifica-se pelo fato de tais modelos mostrarem-se úteis ao propósito de trazer uma melhor compreensão sobre as etapas de desenvolvimento que devem orientar o processo de ensino e aprendizagem, constituindo-se como parâmetros para a análise das dificuldades de aprendizagem dos alunos e também contribuindo para uma visão mais ampliada acerca da própria finalidade do ensino da Geometria.

$\mathrm{Na}$ avaliação da competência matemática realizada pelo Pisa, em 2003 e 2012, foram definidos três níveis de complexidade. Para o primeiro nível, denominado "reprodução", consideraram-se as operações mais comuns, contendo cálculos simples e problemas próprios do cotidiano. Para o segundo, chamado "conexão", as propostas envolveram conceitos e procedimentos matemáticos necessários à resolução de problemas que requeriam a elaboração de modelos para 
a sua resolução. E para o terceiro nível, denominado "reflexão", foram oferecidos problemas mais complexos, que implicavam o desenvolvimento de estratégias matemáticas e conceitos para solucioná-los (ORGANIZACIÓN PARA LA COOPERACIÓN ECONÓMICA Y EL DESARROLLO - OECD, 2013).

Em relação à avaliação de 2003, nota-se, para aquela realizada em 2012, entre outras inovações, uma proposta de maior ênfase ao domínio dos processos, à compreensão dos conceitos e à capacidade de atuar em diferentes contextos e situações propostos em cada um dos domínios de conhecimento avaliados, a partir da apresentação de três grandes novas categorias de processos denominadas: "formulação" de situações matemáticas; "aplicação" dos conceitos matemáticos, do raciocínio e dos procedimentos matemáticos; e "interpretação", aplicação e avaliação dos resultados matemáticos (OECD, 2013).

Tendo como referência a teoria do desenvolvimento de Jean Piaget, o modelo van Hiele, desenvolvido em 1957 por Dina van Hiele-Geldof e seu marido Pierre van Hiele, é composto por:

- cinco níveis de compreensão (nível 0 - visualização; nível 1 - análise; nível 2 - dedução informal; nível 3 - dedução formal; e nível 4 - rigor), que têm por objetivo descrever características próprias do desenvolvimento do pensamento geométrico do aluno;

- cinco orientações chamadas de "propriedades do método" (sequencialidade; progresso ou avanço; intrínseco e extrínseco; linguística; e contribuições mal sucedidas), que dizem respeito à organização dos conteúdos e das estratégias didáticas que devem ser consideradas em cada um dos níveis de compreensão;

- cinco "fases de intervenção" (indagação; orientação dirigida; explicação/explicitação; orientação livre; e integração), que objetivam orientar as situações e intervenções do professor a cada etapa de ensino (HIELE, 1999; CROWLEY, 1987).

Segundo Pires, Curi e Campos (2000), cada nível é marcado por relações específicas estabelecidas entre os objetos 
de estudo e o uso de uma linguagem própria, organizados de forma hierarquizada, por meio da vivência de atividades adequadas que fazem com que o avanço de um nível para outro independa da idade ou maturidade do aluno.

A partir do discurso dos professores do $5^{\circ}$ ano do ensino fundamental, foi realizado o levantamento das dificuldades dos alunos e das estratégias didáticas que diziam utilizar, seguido da análise comparativa a partir dos níveis de competência, complexidade e contexto propostos pelo Pisa 2003 e 2012, bem como pelos níveis de desenvolvimento do pensamento geométrico propostos pelo modelo van Hiele (1999) e Crowley (1987).

As dificuldades apontadas pelos professores com relação aos descritores 1 e 2 encontram-se, respectivamente, nos quadros 2 e 3 . Como resultado das análises comparativas realizadas, obteve-se que todas as dificuldades listadas, em ambos os descritores, correspondem ao nível $\mathbf{0}$ de desenvolvimento do pensamento geométrico segundo o modelo van Hiele e estão Abaixo do nível 1 quando consideramos os níveis de competência apresentados pelo Pisa 2003/2012.

QUADRO 2 - Principais deficiências dos alunos do $5^{\circ}$ ano do ensino fundamental com relação ao descritor 1 do campo geométrico, segundo os participantes da pesquisa

\begin{tabular}{|l|}
\hline PRINCIPAIS DIFICULDADES \\
\hline Confusão entre vértices e arestas, se não estão vendo a figura inteira \\
\hline Dificuldade para distinguir pirâmide de prismas \\
\hline Dificuldade para entender figuras "menos usuais", como cilindro, trapézio e prisma \\
Dificuldade para imaginar as faces, as arestas que não estão visíveis no papel \\
\hline Dificuldade para abstrair \\
\hline Dificuldade para visualizar o que é proposto no livro didático \\
Dificuldade para identificar as figuras nas atividades de planificação
\end{tabular}

Fonte: Dados organizados pelas autoras 
QUADRO 3 - Principais deficiências dos alunos do $5^{\circ}$ ano do ensino fundamental com relação ao descritor 2 do campo geométrico, segundo os participantes da pesquisa

\begin{tabular}{|l}
\hline PRINCIPAIS DIFICULDADES \\
\hline Dificuldade de observar a figura e ver além do que está na frente dele (do aluno) \\
Dificuldade com as figuras que não são do "cotidiano" \\
\hdashline Dificuldade para visualizar/identificar \\
\hline Dificuldade para abstrair \\
Dificuldade para transpor para o concreto \\
Dificuldade para internalizar \\
Dificuldade na leitura/ com o vocabulário/ para entender a situação-problema \\
Dificuldade para representar figuras com um maior número de lados \\
Dificuldade para prestar atenção
\end{tabular}

Fonte: Dados organizados pelas autoras.

Ou seja, as dificuldades apontadas pelos professores remetem aos níveis mais elementares do desenvolvimento do pensamento geométrico proposto pelo modelo van Hiele (1999) e Crowley (1987), sinalizando que, ao longo de praticamente toda a escolaridade, tais dificuldades permaneceram inalteradas, estando muito aquém do esperado para o final do ensino fundamental.

Embora o sistema de ensino apresentasse uma matriz curricular que previa a sequencialidade dos conteúdos geométricos e a progressão vertical dos conteúdos e expectativas de aprendizagem, verifica-se que as dificuldades apontadas pelos professores remetem aos níveis elementares também da referida matriz curricular.

No papel é complicado até nós mesmos olhando para uma figura, no primeiro momento é difícil imaginar as faces que a gente não tá vendo, as vértices, as arestas, então para eles isso é um momento extremamente importante de pegar mesmo a caixa, enfim, desmontar, montar, construir. Acredito que tenha essa dificuldade por essa razão, dificuldade de observar a figura e ver além do que está na frente dele. (Suj. 1)

Eles têm dificuldade na parte de figuras tridimensionais, porque eles confundem muito vértices e arestas, faces eles têm mais claro, e têm realmente, não a maioria, mas têm sim, pirâmide e prisma que são semelhantes. (Suj. 2) 
Quando eu falo conte as arestas e ele fala qual que é a aresta mesmo? Qual que é a aresta? (Suj. 3)

A distinção de pirâmide de prisma eles têm mais dificuldades, aresta é mais fácil. (Suj. 5)

O que eles têm de dificuldade é visualizar. E era um cubo. Mas tinha criança que não identificava. Dificuldade na abstração. Eles não têm essa abstração para visualizar. (Suj. 10)

Você dá uma figura que tenha fundo, ela não consegue transpor aquilo pro concreto, ela não consegue visualizar. (Suj. 20)

Quando você mostra para eles só a figura, igualzinho no livro lá, pedindo para identificar, eles têm dificuldade. (Suj. 24)

Portanto, analisadas tais dificuldades, segundo o modelo van Hiele (1999) e Crowley (1987), os alunos desses professores estariam no primeiro nível do pensamento geométrico, sendo capazes, apenas, de perceber as figuras geométricas em sua totalidade e não a partir de suas partes ou propriedades, ou seja, conseguiriam somente aprender o vocabulário geométrico, identificar e nomear algumas formas, bem como reproduzi-las, sem a necessária observância de suas propriedades, quando solicitado.

Em relação aos níveis de competências propostos pelo Pisa 2003 e 2012, segundo a visão dos professores participantes, seus alunos estariam no nível denominado "abaixo do nível 1", ou seja, não seriam capazes de realizar as tarefas de Matemática mais elementares propostas no Pisa, tais como: responder às perguntas que implicam contextos familiares, ainda que as informações mais relevantes e as perguntas estejam claramente definidas; identificar informações principais; desenvolver procedimentos rotineiros a partir de instruções diretas, em situações explícitas; ou concluir ações que são óbvias e segui-las a partir de um estímulo.

No que se refere aos níveis de complexidade utilizados pelo Pisa 2003, as dificuldades apontadas pelo grupo de professores estariam relacionadas às questões de identificação, 
discriminação e nomeação de figuras geométricas, contempladas no nível denominado "reprodução", estando, portanto, muito aquém do esperado para os níveis "conexões" e "reflexões".

Em relação aos processos definidos pelo Pisa 2012, a partir das dificuldades mapeadas, os alunos do $5^{\circ}$ ano novamente não conseguiriam atingir os níveis mais elementares, haja vista que, além da ausência de conhecimentos sobre os conceitos e conteúdos geométricos, eles também não dispunham de um trabalho voltado para resolução de problemas, conforme se observou no relato de alguns participantes.

É muito difícil você abstrair isso com o aluno porque, quando você apresenta, por exemplo, a figura de um cubo, ele tem dificuldade em visualizar os vértices e as arestas. (Suj. 9)

Só no didático, no livro, sim, eles têm dificuldade. Mas quando você leva para o concreto, não. O que eles têm de dificuldade é visualizar. Tinha a planificação. Que figura que é essa, aberta com todos os lados? Tinha criança que não identificava. (Suj. 10)

A gente trabalhou mesmo só aquela questão de identificar vértices, de saber o que é o vértice. (Suj. 16)

\section{3a ETAPA: DESCRIÇÃO E ANÁLISE DAS ESCOLHAS DIDÁTICAS APONTADAS PELOS PROFESSORES, COM O INTUITO DE SANAR AS DIFICULDADES DOS SEUS ALUNOS}

Nessa etapa, as escolhas didáticas utilizadas pelos participantes, com o intuito de sanar as dificuldades dos alunos, foram também listadas e analisadas por meio da comparação com os níveis de competência, complexidade e contextos propostos pelo Programme for International Student Assessment (Pisa), nas avaliações com concentração em Matemática realizadas em 2003 e 2012, bem como com os níveis de desenvolvimento do pensamento geométrico propostos pelo modelo van Hiele (1999).

Considerando-se que as dificuldades dos alunos derivam, muitas vezes e, sobretudo, de inadequações relacionadas ao ensino ou àquilo denominado pelo modelo van Hiele (1999) também apresentado por Crowley (1987) - de “combinações mal sucedidas", foi necessário verificar, dentre as respostas, 
quais eram as estratégias que os participantes diziam fazer uso, na tentativa de superação das dificuldades percebidas. Dentre as respostas dadas pelos participantes, foram identificadas as propostas didáticas listadas nos Quadros 4 e 5.

\section{QUADRO 4 - Atividades utilizadas pelos professores entrevistados com o objetivo de sanar as dificuldades dos alunos em relação ao descritor 1}

- Trabalhar de forma concreta - manipulando, quantificando, planificando e montando caixas

- Construir/montar figuras tridimensionais com massa de modelar e palitos de churrasco

- Tabular os resultados do Saresp

- Pegar as figuras já montadas

- Cobrar sempre o conteúdo para que os alunos não esqueçam

- Trabalhar a Geometria de forma lúdica

- Fazer atividades para identificar vértices, faces e arestas

- Fazer devolutivas das avaliações

- Vivenciar

- Apresentar as figuras tridimensionais

- Manusear as figuras

- Aprender a parar para pensar

- Fazer dobraduras com papel cartão

- Mostrar o material

- Mostrar a forma de mexer com o material

- Mostrar a figura e pedir para identificar

- Fazer trabalho manual/atividades manuais

- Trabalhar com jogos

- Relacionar o conteúdo de Artes com a Matemática

- Trazer o conceito

- Trabalho com as obras de Tomie Ohtake

- Fazer esculturas com sucata

- Proporcionar contato com a visualização do prisma, da pirâmide

- Trazer materiais de casa

- Olhar revistas, para contextualizar

- Trazer de casa figuras que se parecem com uma pirâmide, com um cilindro

- Conversar sobre as figuras trazidas de casa

- Apresentar o conteúdo várias vezes

- Analisar os resultados dos simulados 
QUADRO 5 - Atividades utilizadas pelos professores entrevistados com o objetivo de sanar as dificuldades dos alunos em relação ao descritor 2

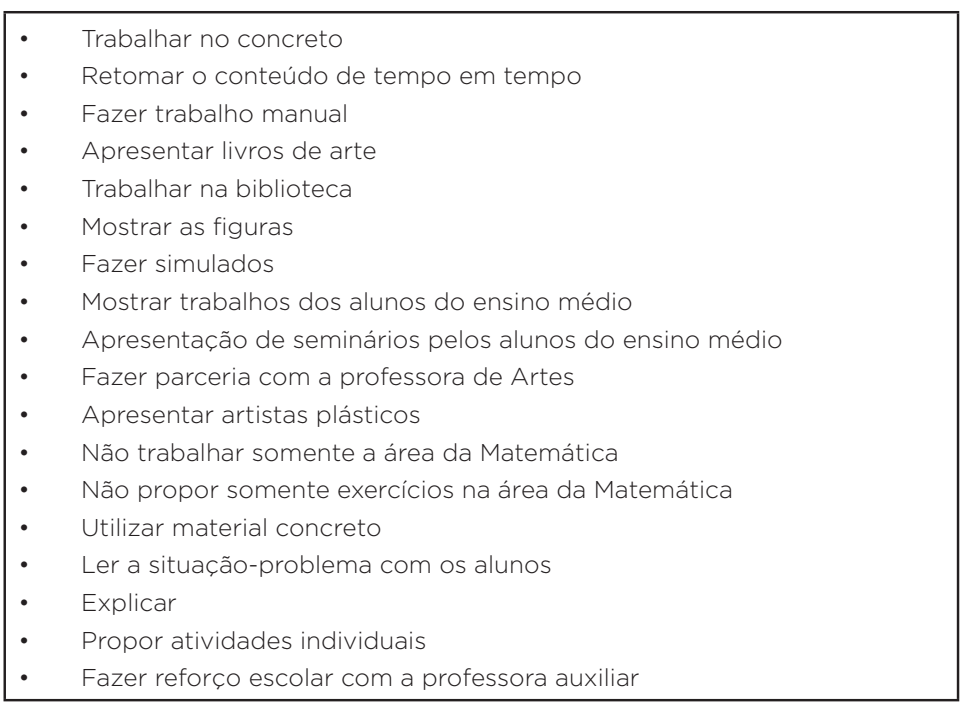

Nos quadros 4 e 5, pode-se observar que, de fato, não havia uma estratégia orientando o ensino da Geometria, mas apenas a enumeração de atividades e técnicas que, sobrepostas, muitas vezes, sequer se relacionavam com as dificuldades dos alunos apontadas.

Em relação às propriedades do modelo van Hiele (1999), no relato dos participantes, não foi possível identificar a presença de uma sequencialidade das propostas mencionadas, de tal modo que as atividades se apresentavam como um fim em si mesmas e não eram organizadas no sentido de possibilitar a ampliação gradativa dos conhecimentos geométricos.

Quanto ao desenvolvimento e uso da linguagem matemática, o que, segundo o modelo, favorece ao mesmo tempo a realização da tarefa e sua resolução e permite o descobrimento das relações pertinentes, a organização temporal das ações e seu controle, também não foi possível identificar, na fala dos professores, um trabalho que apresentasse tais objetivos. Situações de comunicação oral, organizadas de forma sequenciada, não foram consideradas pelos docentes entrevistados.

Segundo o modelo van Hiele (1999), o desenvolvimento progressivo de um vocabulário adequado implica etapas que 
têm início com a comunicação por meio de uma linguagem informal, devendo avançar à medida que as observações e as manipulações se desenvolvem a partir dos conceitos e propriedades geométricas. Tal aspecto pode ser complementado com a ideia trazida por Ausubel (apud ROLDÃO, 2010, p. 66), sobre a necessidade da ampliação intencional do professor acerca dos conhecimentos que os alunos possuem sobre determinado conteúdo, ou seja, "comece onde o aluno está[...]", mas é preciso avançar.

Desse modo, cada nível de desenvolvimento do pensamento geométrico deveria ser composto, de acordo com o modelo, por uma linguagem própria e por símbolos específicos que se relacionam por meio de sistemas próprios. Assim, uma relação estabelecida e considerada adequada em um determinado nível poderia ser modificada em outros níveis posteriores, o que possibilitaria uma apreensão também gradativa da linguagem matemática e, porque não dizer, geométrica.

Ainda em relação à linguagem, Vergnaud (1990, p. 15) também esclarece que, para além dos objetivos de comunicar e representar, há ainda o papel de orientação do pensamento em situações que não se encontram automatizadas, ou "insuficientemente dominadas" pelo aluno, uma vez que a linguagem e os símbolos matemáticos desempenham papel importante para a conceitualização gradativa e para a ação do aluno, sem os quais os esquemas e as situações cairiam em um vazio de sentido.

Portanto, em relação à leitura da situação-problema, segundo Vergnaud (1990), as dificuldades dos alunos apontadas pelo grupo de professores estariam relacionadas não apenas à alfabetização, mas também à falta de conhecimento dos conceitos geométricos e à pouca familiaridade com esse tipo de atividade. Assim, investir em leitura não resolveria o problema, que precisaria ser enfrentado com o ensino de um vocabulário próprio a partir do trabalho com os conceitos geométricos.

Às vezes, eu estou vendo isto daqui, olha, nesta prova, alguns alunos erraram, mas é a palavra. O contorno externo, era da bandeira. Todo mundo sabe que aquilo era um retângulo, mas o contorno externo. É o vocabulário, a maneira de você falar que pega. (Suj. 17) 
[...] a nomenclatura para eles (alunos) é muito difícil [...]. (Suj. 20)

Como eu disse, usamos material concreto e aí fica fácil para os alunos entenderem, o maior problema ainda é eles entenderem a situação-problema, na leitura, então eu leio com eles e aí eles entendem direitinho. (Suj. 14)

Assim, as escolhas didáticas apresentadas pelos professores poderiam, segundo o modelo van Hiele (1999) apresentado detalhadamente por Crowley (1987), ser classificadas como "combinações mal sucedidas", em virtude da ausência de adequação das propostas às necessidades dos alunos.

Em relação às fases de intervenção do professor, propostas pelo casal van Hiele (1999), novamente não foi possível vislumbrar, no relato dos participantes, intervenções que privilegiassem o diálogo e situações de observação a partir de critérios previamente definidos, bem como o levantamento de perguntas e a apresentação gradativa de um vocabulário adequado.

De acordo com o mesmo modelo, as intervenções dos professores deveriam contemplar simultaneamente dois objetivos: ao professor, o entendimento do nível de conhecimento que seus alunos possuem sobre os conteúdos da Geometria; e aos alunos, o conhecimento sobre o modo como serão desenvolvidos os conteúdos do curso.

Portanto, o que restou da presente análise foi a ausência de intervenções planejadas, que, segundo Berbigier (2010), permitiriam aos alunos um conhecimento gradativo das propriedades específicas dos elementos figurais e generalizações a partir da observação criteriosa das semelhanças e diferenças.

Esse aspecto também corrobora os estudos desenvolvidos por Clements e Sarama (2000), que observaram que as diferenças acerca dos conhecimentos geométricos, entre as crianças da pré-escola (4 a 6 anos de idade) e os estudantes do $6^{\circ}$ ano, foram mínimas, ensejando que nova estruturação curricular seja considerada a fim de que o trabalho de cada etapa da escolaridade possa, de fato, resultar na ampliação das aprendizagens dos alunos.

A desconsideração, por parte dos professores, dos conhecimentos prévios dos seus alunos e dos objetivos do ensino 
da Geometria também se mostrou presente. Dessa forma, não vislumbrando os objetivos a serem atingidos, ainda que houvesse uma matriz curricular elaborada pelo sistema de ensino, as ações empreendidas pouco contribuíam para que os conhecimentos adquiridos se constituíssem como ponto de partida para investigações mais elaboradas.

Segundo afirma Berbigier (2010), os alunos, com base em suas experiências anteriores, poderiam revelar seus pensamentos e modificar seus pontos de vista sobre as estruturas trabalhadas, conseguindo, por exemplo, por meio de comparações e demonstrações apoiadas no material, discutir entre si e com o professor as relações estabelecidas entre as figuras estudadas anteriormente e suas propriedades, tornando assim evidente aos alunos o sistema de relações.

A partir do discurso dos professores, observou-se que o tema recorrente era a abstração da Geometria versus a necessidade/realização de um trabalho concreto, conforme se depreende do relato de alguns participantes:

Quando trabalha a Geometria é bastante lúdica a aula, porque a criança não entende uma figura. Normalmente eu uso massa de modelar e palito de churrasco. Eu jogo para eles. Eles acham que nós vamos brincar. (Suj. 10)

É assim. Quando trabalha só giz, papel, eles apresentam, têm dificuldades, mas a partir do momento que você traz para o concreto e mostra para eles material ou a forma de mexer com eles. A gente faz no papel cartão. Então, no primeiro momento, quando você mostra para eles só a figura, igualzinho no livro lá, pedindo para identificar, eles têm dificuldade, mas trabalhando no concreto não é dificuldade. (Suj. 24)

Aquilo é abstrato, mas ele fez no concreto, então, aquilo fica guardado na cabecinha dele. Ele construiu o sólido geométrico, então, ele consegue abstrair na hora da prova. Ele não constrói, ele se embaralha [...] Isto daqui tem que ser trabalhado muito no concreto. (Suj. 18) 


\section{ETAPA: HIPÓTESES SOBRE AS DIFICULDADES \\ DOS ALUNOS EM GEOMETRIA, FORMULADAS PELOS PROFESSORES}

Em relação às dificuldades identificadas e hipóteses formuladas pelos professores, a incapacidade do aluno de lidar com conteúdos abstratos figurava de forma primordial, reforçando a ideia de que os alunos do $5^{\circ}$ ano só seriam capazes de aprender Geometria por meio da livre observação e manipulação do material pedagógico.

É o que eu falo. Tudo o que está no abstrato eles não aprendem. (Suj. 24)

Tem crianças que têm uma dificuldade terrível, você dá uma figura que tenha fundo, ela não consegue transpor aquilo pro concreto, ela não consegue visualizar, de jeito nenhum, aí você mostra o fundo da caixa, o fundo do armário, o fundo de uma caixa de vidro, é isso daqui, é como se fosse uma caixa de vidro, mas é difícil, eu acho que é a imaturidade deles. [...] ele vive cercado com formas geométricas, tridimensionais, bidimensionais, e assim por diante, só que ele não aprendeu a parar e pensar, né, nos lados, quanto lados tem um armário? (Suj. 20)

A criança ainda não sabe. Ela não sabe porque ela não manuseou. Ela não sabe se não manuseou. (Suj. 23)

No que tange às atividades/técnicas utilizadas pelos professores, novamente a dificuldade dos alunos para lidar com conceitos considerados abstratos se colocava como justificativa para o uso indiscriminado do chamado material concreto, como forma prioritária de sanar tais dificuldades.

[...] acredito que não tem como você trabalhar esse conteúdo sem trabalhar aí concretamente [...] difícil imaginar as faces que a gente não está vendo. (Suj. 1)

[...] quando começamos a trabalhar com vértices, arestas, se eles não estão vendo, eles não conseguem. Então você tem que apresentar várias vezes. Aqui eu não colocaria que eles apresentam estas dificuldades. (Suj. 15) 
[...] eles precisam ter o visual, se eles não tiverem ali o visual não adianta só falar pra eles, tem que estar vendo, precisa enxergar, pra poder saber o que é cada coisa. (Suj. 19)

As figuras bidimensionais, ao meu ver como professora, nós temos que trabalhar no concreto. Você tem que trazer isso para o aluno visualizar. (Suj. 9)

Do mesmo modo, quando a dificuldade dos alunos era negada pelos participantes, o sucesso era novamente atribuído à manipulação de material concreto e sequer eram mencionadas as intervenções realizadas pelos professores na mediação entre os alunos, o material e os conteúdos geométricos. Dessa forma, o material parecia sempre ser um fim em si mesmo e a Geometria passava a ser representada pelo grupo como um conteúdo abstrato, teórico e pouco acessível aos alunos.

Esse ano a escola adquiriu um kit com as figuras e isso facilitou o trabalho. Quando eles pegaram as figuras já montadas, a figura é bonita, chama a atenção e isso ajudou mais. (Suj. 3)

Quando trabalha só giz, papel, eles apresentam, têm dificuldades, mas a partir do momento que você traz para o concreto e mostra para eles material ou a forma de mexer com eles. (Suj. 24)

Porque os alunos trazem os materiais de casa e, para contextualizar, é pedido para que vejam em revistas, ou tragam de casa figuras que parecem com uma pirâmide, com um cilindro, e aí a gente conversa. (Suj. 14)

Nos descritores um e dois que trabalha tridimensional e o bidimensional nas pirâmides, nós fizemos um trabalho manual com eles, atividades manuais, e acho que eles não tiveram problemas não, eles até gostaram. (Suj. 4)

Esse era um consenso presente no grupo que, no entanto, não garantia sucesso à aprendizagem dos alunos, posto que o caráter abstrato da Geometria, em vez de ser colocado como meta a ser atingida com o trabalho desenvolvido, era 
percebido como inadequado, impróprio e, portanto, precisava ser neutralizado ou minimizado por meio de um ensino essencialmente prático.

Observou-se que as propostas oferecidas pelos professores pareciam reduzir o ensino da Geometria apenas à manipulação indiscriminada do material concreto, sem o aprofundamento necessário sobre os conceitos e propriedades que compõem as figuras bidimensionais e tridimensionais, além do fato de não contemplarem situações que envolvessem a resolução de problemas, com o objetivo de garantir uma aprendizagem que permitisse aos alunos do $5^{\circ}$ ano "formular hipóteses matemáticas, a partir de problemas envolvendo diferentes contextos"; "aplicar conhecimentos matemáticos para resolver problemas do cotidiano"; e "interpretar adequadamente os resultados obtidos em diferentes contextos".

Diante do panorama apresentado, somava-se ao discurso dos participantes uma ideia de "concretude" das atividades e técnicas utilizadas no ensino da Geometria que decorria da apropriação reduzida de teorias apoiadas nas estruturas cognitivas de uma epistemologia genética, sobretudo em relação à crença de que os alunos do $5^{\circ}$ ano só aprenderiam os conteúdos geométricos manipulando material, justamente por serem considerados "egocêntricos" e "imaturos".

Do primeiro ao quinto ano é a base e a criança precisa, se você for pensar, ela precisa ver para fazer. Ela precisa fazer com a mão dela. Não pode ver o outro fazer. Nós adultos conseguimos ler o texto e utilizar o texto. Nem toda criança faz isso. Não faz parte da maturação dela. 0 aluno aprende aquilo que ele faz, principalmente o aluno até o quinto ano. Nós temos que considerar a maturação cognitiva dessas crianças. (Suj. 23)

[...] eu acho essa turma mais infantil. Eles são mais infantis, imaturos. As outras turmas que eu tive eram avançados. Porque é assim, nós ficamos no ciclo, quartos e quintos anos. Para mim eles seriam o quarto ano e não o quinto ano. Na verdade, se você for analisar, eles estão na idade certa. Os outros eram avançados para idade, em termos gerais, de despertar. [...] a maturidade é própria da idade. (Suj. 10) 
[...] não [as dificuldades não permanecem ao longo do ano], acredito que com o tempo, também pelo amadurecimento deles. [...] a gente ainda vai rever questões e vai retomando várias coisas e eles vão assimilando. [...] talvez uma coisa que eles viram antes e tiveram uma certa dificuldade, com o tempo isso vai amadurecendo, a ideia vai amadurecendo. (Suj. 1)

[...] muitos alunos ainda precisam dessa visualização, desse concreto. Ele olha uma fração, ele vai fazer o desenho para ver que parte dessa fração. [...] eles ainda não abstraem com autonomia total. [...] eu acredito que é um processo. [...] isto vai ter uma sequência que o aluno vai resolvendo essas questões, essas dificuldades, e ele vai amadurecendo. (Suj. 9)

[...] eles amadurecem também. A cabeça vai ficando pronta para algumas situações que, no momento anterior, não estava. Eles amadurecem e conseguem desenvolver. (Suj. 12)

[...] o quinto ano eles são um pouco mais imaturos, eles têm um pouco mais de dificuldade em raciocínio lógico em abstrair ou mesmo de trabalhar no concreto, até de trabalhar no concreto.

(Suj. 19)

Tais hipóteses não encontram sustentação na proposta dos modelos van Hiele (1999) e do Pisa (2003 e 2012), que determinam que a aprendizagem se dá não em razão de um estágio maturacional definido biologicamente (faixa etária), mas, sobretudo, a partir da qualidade das propostas oferecidas, que, aliadas às intervenções do professor, permitirão o desenvolvimento gradativo do pensamento geométrico.

Ainda que analisadas as dificuldades dos alunos à luz da epistemologia genética de Jean Piaget, as hipóteses apontadas pelo grupo de professores não se sustentavam, uma vez que indicavam a descrição do estádio pré-operatório, que corresponderia à faixa etária de 2 a 7 anos, haja vista que a principal dificuldade referia-se à incapacidade dos alunos de visualizar todos os lados de uma figura tridimensional, quando havia lados que não estavam visíveis nas ilustrações trazidas nos livros, por exemplo. 
No caso aqui, identificar. Quer dizer, com o que eu vou me preocupar aqui? É com a identificação. Eu não vou me preocupar aqui se ele consegue resolver problema com prisma, com a... não! Eu não vou! Eu vou só me preocupar com a identificação. (Suj. 13)

Davis e Oliveira (2010) esclarecem que o estádio pré-operatório é marcado pelo egocentrismo, que impede as crianças de considerarem outros pontos de vista, bem como pela transdedutividade (a criança sempre partirá de sua experiência particular e por isso tornar-se-á incapaz de atingir a dedução e indução), pela incapacidade da noção de conservação (quando se muda a aparência dos objetos, mesmo sendo iguais, passa a acreditar na mudança de quantidade, peso, volume) e pela irreversibilidade (não consegue ser capaz de retornar mentalmente ao ponto de partida).

Nesse sentido, a ideia de um ensino exclusivamente prático e absolutamente contextualizado no cotidiano imediato do aluno remete a uma concepção de desenvolvimento que não corresponderia à faixa etária dos alunos do $5^{\circ}$ ano do ensino fundamental (10/11 anos), haja vista que, segundo a Epistemologia Genética de Jean Piaget, esses alunos deveriam estar situados no estádio denominado operatório concreto (7 a 12 anos de idade). Essa fase é caracterizada justamente pela diminuição do egocentrismo, permitindo à criança maior flexibilidade e mobilidade no pensamento, explicitadas pela necessidade de esta expor logicamente suas ideias e suas ações conforme explica Rappaport (1981), ainda que recorrendo ao uso de materiais e da observação como ponto de apoio para o desenvolvimento de novas formas de comunicação e aprendizagem, mas não de forma prioritária, como se observava no estádio anterior, segundo Davis e Oliveira (2010).

Ademais, conforme estudos realizados por Clements et al. (1999) e Clements e Sarama (2000), crianças a partir dos quatro anos de idade seriam capazes de, por meio da observação de formas geométricas, classificá-las e, a partir de um protótipo visual, nomear algumas de suas propriedades, de modo que a capacidade de "ver" instantaneamente as formas no mundo seria o resultado, e não a origem, do conhecimento geométrico. A crença desses professores de que os seus alunos 
tinham pouco ou nenhum conhecimento acerca da identificação dos elementos figurais é incorreta, pois, conforme apontam Clements et al. (1999) e Clements e Sarama (2000), até mesmo crianças pré-escolares apresentam tal conhecimento de formas geométricas simples.

Desse modo, a justificativa para as dificuldades dos alunos, conforme explica Wirszup (apud CLEMENTS et al., 1999, p. 208), decorreria, em parte, do fato de que a eles não foram oferecidos problemas geométricos em seus primeiros anos, de tal forma que o "período de inactividade prolongada", e ainda considerando as séries iniciais, levaria àquilo que Fuys, Geddes e Tischler (apud CLEMENTS et al., 1999, p. 208) denominaram de "crianças carentes geometricamente".

Outrossim, a qualidade das propostas oferecidas e a limitação observada acerca das atividades propostas pelo grupo entrevistado dificultariam o desenvolvimento de novos esquemas para demais aprendizagens, corroborando os estudos realizados por Clements et al. (1999) e Clements e Sarama (2000), que constataram que um ensino pautado exclusivamente no contexto imediato do aluno e apoiado nos materiais escolares, comumente oferecidos, poderia resultar na fossilização de protótipos rígidos que, por sua vez, dificultariam o avanço das aprendizagens.

Em síntese, a análise do discurso dos professores evidenciou uma característica importante na representação social que possuíam sobre a Geometria: o conflito entre o caráter abstrato e o caráter prático dos conteúdos geométricos, o que, em função do desconhecimento dos fundamentos e dos processos de aprendizagem da criança, bem como de suas possibilidades de abstração, resultou em uma representação de impossibilidades de aprendizagem.

No mesmo sentido, em relação ao modelo van Hiele (1999), os relatos dos professores não comportavam a sequencialidade indicada pelo modelo para o trabalho com os conteúdos geométricos, conforme se observa da fala de um participante:

[...] existem para cada ano, existem algumas competências, né? Que a gente usa, a gente tem que cumprir algumas expectativas para abranger essas competências e habilidades [...] quando eu 
entrei aqui, eu sofri... tive muita dificuldade, por causa disso mesmo. Você poderia escolher qualquer expectativa. Se você quisesse começar, por exemplo, por essa de porcentagem no começo do ano, no quarto ano, você poderia, né? [...] isso me confundiu muito, isso me deixou perdida. (Suj. 11)

Nesse sentido, conforme aponta Crato (2011, p. 247),

[...] estudos modernos da cognição têm mostrado [...] que o alcance de objetivos mais ambiciosos depende criticamente da sequência de actividades de aprendizagem em que os processos básicos têm necessariamente precedência,

razão pela qual se faz necessária a explicitação dos conteúdos e das finalidades de seu ensino a partir não apenas da apresentação das competências que se pretende desenvolver, mas, sobretudo, da transposição que necessita ser realizada para o plano das estratégias didáticas.

Confirmou-se, nesse sentido, a ideia proposta por Crato (2011, p. 251) acerca do processo de negação da abstração dos conteúdos matemáticos, principalmente por meio de orientações curriculares nacionais que, pautadas exclusivamente pela aprendizagem de contexto, resultam na ideia de que a "a verdadeira aprendizagem só ocorreria em situações reais”, o que é um equívoco, porque nesse processo de negação da abstração negam-se também aos alunos a possibilidade de contextualizações internas à própria Matemática e a apropriação gradativa de porções do pensamento geométrico.

\section{CONSIDERAÇÕES FINAIS}

Inicialmente, cabe destacar que o perfil dos entrevistados em relação ao tempo de magistério, à formação e à distribuição quanto ao posicionamento das escolas em que atuavam não foi relevante para a identificação ou não das dificuldades dos alunos e, ainda, corrobora a deficiente formação em Geometria enquanto estudantes e professores, apontada por Nacarato (2000).

Os resultados obtidos com o presente estudo evidenciaram uma rede de significados sintetizados nos seguintes 
contextos: ausência de um repertório mínimo de conhecimento construído, por esse grupo, sobre os conceitos e conteúdos geométricos; categorização negativa da Geometria, considerada abstrata/difícil/pouco acessível aos alunos; ensino essencialmente prático, desconectado dos conceitos e conteúdos geométricos; redução do objetivo do ensino da Geometria às situações de identificação e nomeação dos elementos figurais; e sua aplicação prática, em contextos também reduzidos, que se limitavam à nomeação e identificação das figuras mais usuais.

As situações que envolviam a livre manipulação de material concreto e a contextualização a partir das situações do cotidiano do aluno foram as atividades e técnicas mais comumente apresentadas. Contudo, uma vez que os critérios (conceitos e propriedades geométricas) que deveriam orientar tais propostas não se mostravam claramente colocados como finalidade a ser alcançada, o que se vislumbrou foi o esvaziamento daquilo que deveria ser ensinado. Não ficou claro, por meio das análises realizadas, o que deveria ser observado, o que deveria ser relacionado, o que deveria ser construído e tampouco o porquê.

À medida que os professores buscavam "neutralizar" a "abstração" dos conceitos geométricos (que são teóricos e necessitam de marco instrucional), os materiais pedagógicos passavam a ocupar o lugar das estratégias e do próprio objeto a ser estudado, tomando o lugar do início, dos meios e dos fins do ensino.

A abstração da Geometria constituiu-se, portanto, o "não familiar" e, a partir das ancoragens, que são sempre históricas, tornou-se familiar justamente por meio de afetos negativos, que a classificaram como imprópria e inadequada para ser ensinada. Tal categorização, entrelaçada a outras famílias de representações sobre crianças e desenvolvimento infantil, resultou na construção de uma representação de incapacidade dos alunos do $5^{\circ}$ ano para a aprendizagem dos conteúdos geométricos.

O resultado de tal classificação fez com que o objetivo do seu ensino fosse modificado e passasse a orientar as escolhas didáticas dos professores, que visavam, sobretudo, 
combater os efeitos daquilo que consideravam abstrato, ou seja, passavam a combater o próprio objetivo do seu ensino. A abstração da Geometria deixava de ser uma característica e meta a ser atingida para tornar-se um emblema.

Nesse sentido, analisar os resultados das avaliações em larga escala pressupõe, portanto, um olhar mais abrangente sobre as condições que envolvem o trabalho docente, os processos de ensino e aprendizagem e, principalmente, as representações que se colocam perante as diferentes áreas de conhecimento que compõem o fazer/ser docente.

Parafraseando Werle (2010, p. 23), a análise realizada em conjunto com os professores permitiu destacar as laranjeiras, suas flores e seus frutos, a partir dos parâmetros gerais da floresta, oferecidos pelos relatórios dos resultados das avaliações em larga escala, constituindo-se como ponto de partida para inúmeras reflexões sobre os processos de ensino e aprendizagem dos conteúdos geométricos.

\section{REFERÊNCIAS}

ARRUDA, Angela. Despertando do pesadelo: a interpretação. In: MOREIRA, A. S. P.; CAMARGO, B. V.; JESUINO, J. C.; NÓBREGA, S. M. Perspectivas teórico-metodológicas em representações sociais. João Pessoa: Editora UFPB, 2005.

BERBIGIER, Bruna Silveira. Construindo conceitos geométricos a partir de histórias infantis. In: ENCONTRO REGIONAL DE ESTUDANTES DE MATEMÁTICA DO SUL, 16., 3-7 junho de 2010, Porto Alegre. Anais... Porto Alegre: EdiPUCRS, 2010. Disponível em: <http://www.pucrs.br/edipucrs/ erematsul/comunicacoes/6BRUNASILVEIRABERBIGIER.pdf>. Acesso em: $1^{\circ}$ out. 2012.

CLEMENTS, Douglas H.; SWAMINATHAN, Sudha; HANNIBAL, Mary Anne Zeitler; SARAMA, Julie. Young children's concepts of shape. Journal for Research in Mathematics Education, v. 30, n. 2, p. 192-212, 1999. Disponível em: $<$ http://gse.buffalo.edu/fas/Clements/files/JRME_Shape_1999.pdf>. Acesso em: dez. 2012.

CLEMENTS, Douglas H.; SARAMA, Julie. Young children's ideas about geometric shapes. Teaching Children Mathematics, v. 6, n. 8, p. 482-488, 2000. Disponível em: <http://gse.buffalo.edu/org/buildingblocks/writings/YC_ Ideas_Shapes.pdf>. Acesso em: dez. 2012.

CRATO, Nuno. Ensinar matemática temperando a experiência com as recomendações da ciência moderna. In: CONFERÊNCIA INTERNACIONAL ENSINO DA MATEMÁTICA: QUESTÕES E SOLUÇÕES, 2008, Lisboa. Anais... Lisboa: Fundação Calouste Gulbenkian, 2011. p. 241-267. 
CROWLEY, Mary L. The van Hiele model of the development of geometric thought. In: LINDQUIST, Mary Montgomery (Ed.). Learning and teaching geometry, K-12: 1987 yearbook. Reston, VA.: National Council of Teachers of Mathematics, 1987. p. 1-16.

DAVIS, Claudia; OLIVEIRA, Zilma de Moraes Ramos de. Psicologia na educação. 3. ed. São Paulo: Cortez, 2010.

HIELE, Pierre M. van. Developing geometric thinkin through activities that begin with play. Teaching Children Mathematics, v. 5, n. 6, p. 310 -316, Feb. 1999.

MOSCOVICI, Serge. Representações sociais: investigações em psicologia social. Tradução de Pedrinho A. Guareschi. 7. ed. Petrópolis: Vozes, 2010.

NACARATO, Adair Mendes. Educação continuada sob a perspectiva da pesquisa-ação: currículo em ação de um grupo de professores ao aprender ensinando geometria. 2000. Tese (Doutorado) - Universidade Estadual de Campinas, Campinas, 2000.

ORGANIZACIÓN PARA LA COOPERACIÓN ECONÓMICA Y EL DESARROLLO. El programa PISA de la OECD: qué es y para qué sirve. Disponível em: <http:/ www.oecd.org/pisa/39730818.pdf>. Acesso em: 12 dez. 2012.

ORGANIZACIÓN PARA LA COOPERACIÓN ECONÓMICA Y EL DESARROLLO. PISA 2003 - Technical report. 2005. Disponível em: <http://www.oecd.org/ edu/preschoolandschool/programmeforinternationalstudentassessme ntpisa/35188570.pdf>. Acesso em: 15 fev. 2013.

ORGANIZACIÓN PARA LA COOPERACIÓN ECONÓMICA Y EL DESARROLLO. PISA Country profiles. 2006. Disponível em: <http://pisacountry.acer.edu.au/ displayPdf.php?cycle $=2 \&$ cycleChange $=2 \&$ hostCountry $=A U \&$ countries []$=\&$ regions $[=\& \mathrm{cc}[0]=$ BR\&indicator $=2 \&$ domain $=1 \&$ belowLvl1=on\&Lvl1=on\&Lvl2=on\&Lvl3=on\&Lvl4=on\&Lvl5=on\&Lvl61=on\&sortOrder=SUM\&2_options=true $\&$ theme $=1 \& \mathrm{cmd}=$ storeGraphRequest $\&$ requestid $=1350446854437 \&>$. Acesso em: 15 fev. 2013.

ORGANIZACIÓN PARA LA COOPERACIÓN ECONÓMICA Y EL DESARROLLO. PISA 2012 assessment and analytical framework: mathematics, reading, science, problem solving and financial literacy. 2013. Disponível em: <http://www. oecd.org/pisa/pisaproducts/PISA\%202012\%20Hyperliens\%20.pdf>. Acesso em: 15 fev. 2013.

PIMENTA, Sonia de Almeida; DIAS, Adelaide Alves. Profissionalização docente: expectativas em direção à profissionalidade. In: SOUSA, C. P. D.; VILLAS BÔAS, L. P. S.; ENS, R. T. (Org.). Representações sociais: políticas educacionais, justiça social e trabalho docente. Curitiba: Champagnat; São Paulo: Fundação Carlos Chagas, 2012. p. 111-132.

PIRES, Celia Maria Carolino; CURI, Edda; CAMPOS, Tania Maria Mendonça. Espaço \& forma: a construção de noções geométricas pelas crianças das quatro séries iniciais do ensino fundamental. São Paulo: Proem, 2000.

RAPPAPORT, Clara Regina. Modelo piagetiano. In: RAPPAPORT, Clara Regina; FIORI, Wagner da Rocha; DAVIS, Cláudia. Psicologia do desenvolvimento - Teorias do desenvolvimento: conceitos fundamentais. São Paulo: EPU, 1981. v. 1. 
ROLDÃO, Maria do Céu. Estratégias de ensino: o saber e o agir do professor. 2. ed. Vila Nova de Gaia, Portugal: Fundação Manuel Leão, 2010.

SOUSA, Clarilza Prado de et al. Dificuldades recorrentes dos alunos do $5^{\circ}$ ano do ensino fundamental em matemática. Estudos em Avaliação Educacional, São Paulo, v. 23, n. 53, p. 198-221, set./dez. 2012.

SPINK, Mary Jane. Desvendando as teorias implícitas: uma metodologia de análise das representações sociais. In: GUARESCHI, P.; JOVCHELOVITCH, S. Textos em representações sociais. 13. ed. Petrópolis: Vozes, 2012. p. 95-118.

STANICH, Karina Alves Biasoli. O processo de ensino e aprendizagem da geometria: representações sociais de professores do $5^{\circ}$ ano do ensino fundamental. 2013. Dissertação (Mestrado) - Pontifícia Universidade Católica de São Paulo, São Paulo, 2013.

VERGNAUD, Gerard. La teoría de los campos conceptuales. Recherches en Didáctique des Mathématiques, v. 10, n. 2, 3, p. 133-170, 1990.

WERLE, Flávia Obino Correa (Org.). Avaliação em larga escala: foco na escola. São Leopoldo: Oikos; Brasília, DF: Liber Livro, 2010.

KARINA ALVES BIASOLI STANICH

Doutoranda do Programa de Pós-Graduação em Educação: Psicologia da Educação da Pontifícia Universidade Católica de São Paulo (PUC-SP), São Paulo, São Paulo, Brasil karinabiasoli@yahoo.com.br

CLARILZA PRADO DE SOUSA

Professora Titular da Pontifícia Universidade Católica de São Paulo (PUC-SP), São Paulo, São Paulo, Brasil

clarilza.prado@uol.com.br 
